\title{
BMJ Open Case-control study of anaemia among middle-aged and elderly women in three rural areas of China
}

\author{
Pengkun Song, Lixiang Li, Qingqing Man, Chunrong Wang, Liping Meng, \\ Jian Zhang
}

To cite: Song P, Li L, Man Q, et al. Case-control study of anaemia among middle-aged and elderly women in three rural areas of China. BMJ Open 2014;4:e004751. doi:10.1136/bmjopen-2013004751

- Prepublication history for this paper is available online. To view these files please visit the journal online (http://dx.doi.org/10.1136/ bmjopen-2013-004751).

Received 31 December 2013 Revised 7 July 2014 Accepted 21 July 2014

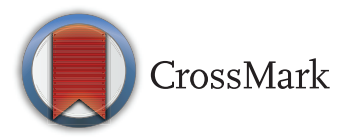

Elderly and Clinical Nutrition Laboratory, Institute of Nutrition and Food Safety, Chinese Center for Disease Control and Prevention, Beijing, China

Correspondence to Professor Jian Zhang; zhjian6708@aliyun.com

\section{ABSTRACT}

Objectives: To propose a feasible suggestion to reduce the high prevalence of anaemia in middle-aged and elderly women by investigating risk factors, particularly nutritional factors, and analysing the effect on anaemia in three different rural areas of China.

Design: A case-control study.

Setting: Three counties of China.

Participants: Women aged 50-75 years in the three counties.

Main outcome measures: Adjusted OR $(95 \% \mathrm{Cl})$ of anaemia associated with diet, lifestyle and blood biochemical indices.

Results: Compared with controls, women with anaemia had lower body mass index (22.1 (3.2) $\mathrm{kg} / \mathrm{m}^{2}$ vs 23.2 (3.5) $\mathrm{kg} / \mathrm{m}^{2} ; p<0.001$ ), a higher experience of shortage of food $(45.0 \%$ vs $36.5 \% ; p<0.001)$, less soy food intake $(0.5(0.3,26.7) \mathrm{g} /$ day vs $5.6(0.4,27.8) \mathrm{g} /$ day; $\mathrm{p}<0.048)$, lower serum iron (13.4 (5.4) $\mu \mathrm{mol} / \mathrm{L}$ vs $16.4(5.7) \mu \mathrm{mol} /$ $\mathrm{L} ; \mathrm{p}<0.001)$, lower ferritin (109.6 (85.6) $\mathrm{ng} / \mathrm{mL}$ vs 131.0 $(92.0) \mathrm{ng} / \mathrm{mL} ; p<0.001)$, lower transferrin saturation levels (22.5 (9.5)\% vs $26.8(9.6) \% ; p<0.001)$ and higher levels of free erythrocyte protoporphyrin (42.4 (21.2) $\mu \mathrm{g} / \mathrm{dL}$ vs 39.6 (17.8) $\mu \mathrm{g} / \mathrm{dL} ; \mathrm{p}<0.001)$. Anaemia was significantly associated with $\mathrm{BMI}(\mathrm{OR}=0.90,95 \% \mathrm{Cl}(0.87$ to 0.92$))$, food shortage experience $(\mathrm{OR}=1.39,95 \% \mathrm{Cl}(1.15$ to $1.69)$ ), total protein $(\mathrm{OR}=0.66,95 \% \mathrm{Cl}(0.54$ to 0.80$))$, Albumin ( $\mathrm{OR}=0.72,95 \% \mathrm{Cl}(0.59$ to 0.87$)$ ) in univariate analysis. Multivariate analysis showed that body mass index, experience of food shortage, total protein and albumin were independently related to anaemia.

Conclusions: Among middle-aged and elderly women in rural China, the nutrition status of anaemic cases is far below that of controls. Lower body mass index and a greater experience of food shortage are closely related to anaemia. Improving the blood protein status by consuming protein-sufficient foods such as soy food is a feasible approach for elderly anaemic women. Further research is needed on the effect of chronic inflammation and infectious disease on anaemia in elderly women in rural China.

\section{INTRODUCTION}

Anaemia affects about one-quarter of the world's population, especially pregnant women, young children and elderly people. ${ }^{1}$

\section{Strengths and limitations of this study}

- The main strength of the study is the detailed analysis of the nutritional status of elderly women in rural China.

- The main limitation was the difficulty to exclude anaemia caused by chronic diseases and the recall bias was inevitable in the observation nature of the study.

- No sufficient evidence to support our claim that eating habits and physical exercises were stable over time.

- Some continuous variables were categorized for analysis to increase the possibility of residual confounding and decrease the precision and power of the study.

In America, $10.2 \%$ of women aged 65 and older are anaemic. ${ }^{2}$ The prevalence among independent community-dwelling persons is more than $20 \%$ and among hospitalised geriatric patients the rate is up to $40 \% .^{3}$ In China the results of several surveys indicate that the prevalence of anaemia in elderly people is $20-39 \%$, reaching $60 \%$ in some very poor rural areas. ${ }^{4}$

In recent years, with the rapid development of the economy, there have been remarkable changes in dietary patterns and lifestyle in China, particularly in urban regions. With the improvement in living standards, the rate of malnutrition in elderly people has decreased significantly. However, the problem of undernutrition such as anaemia is still very severe among elderly people in rural areas. Data from the 2002 China National Nutrition and Health Survey (CNNHS) indicated that the prevalence of anaemia in women aged 60 years and older in rural areas was almost 1.5 times that of urban women of the same age group. Compared with data from the 1992 National Nutrition Survey, the reduction in the prevalence of anaemia in elderly urban women reached $33.6 \%$ while, for elderly women in 
rural areas, the reduction was just $4.8 \%$. It is therefore important to investigate the risk factors for anaemia in elderly women in rural areas of China and to provide suggestions for improving the health status of this population.

Elderly people are more prone to becoming anaemic ${ }^{5}$ which adversely affects muscle strength ${ }^{6}$ physical performance, ${ }^{7}$ cognition $^{8}$ and longevity ${ }^{9}$ and thus adds an economic burden on society. The physiological and metabolic characteristics of elderly people are quite different from other populations. In elderly people the metabolic rate slows down and they are more vulnerable to environmental deficiencies and recovery becomes more difficult. The causes are complicated, particularly those involving blood loss caused by some chronic diseases. However, some studies have shown that anaemia in elderly people is also closely related to nutritional status, ${ }^{10}$ especially iron-deficient anaemia (IDA). We proposed that, among all the reasons, malnutrition-low bioavailability of iron caused by a poor quality diet (simple foods composed particularly of low animal or soy food consumption) - may be the main reason for anaemia in elderly women living in most rural areas of China. We undertook a case-control study to investigate the nutritional causes of anaemia in elderly women. It is hoped that the results will promote an increasing capacity for elderly individuals and communities to prevent anaemia and provide useful experience for making recommendations for this high-risk population.

\section{METHODS}

Study populations and sample collection

Women aged 50-75 years were selected from three representative rural areas of China according to the 2002 CNNHS. ${ }^{11}$ The three rural areas were Qidong, Jiangsu Province (East China), Huangling, Shaanxi Province (Northwest China) and Xiuning, Anhui Province (Middle China). In each county surveyed the selection process included two steps. In the first stage, the basic personal health survey, which included questions about demographic characteristics, disease history, smoking, drinking, physical activity and sleeping, was undertaken among all volunteers aged 50-75 years. In addition, finger blood haemoglobin concentration was measured in all volunteers. Women with serious diseases were excluded according to the exclusion criteria. Women with haemoglobin levels of $90-120 \mathrm{~g} / \mathrm{L}$ were selected as subjects in the case group and those with haemoglobin levels $\geq 130 \mathrm{~g} / \mathrm{L}$ were recruited to the control group. The subjects in the two groups were matched for age. In the second stage, after a 10-14 h fast, venous blood samples were collected in the morning and questionnaires on diet, life style, medical history and physical activity were completed. Food and nutrient intake was calculated based on consecutive individual three-day food records. In order to evaluate the whole diet quality we calculated the dietary balance index (DBI). ${ }^{12}$ Anthropometric measurements including height, weight and waist circumference were measured at the working site. Height was measured to the nearest centimetre without shoes, weight was measured to the nearest $0.1 \mathrm{~kg}$ in light clothing and waist circumference was measured midway between the lower rib margin and the superior anterior iliac spine to the nearest $0.5 \mathrm{~cm}$ with a nonstretching tape applied horizontally. ${ }^{13}$ Body mass index (BMI) was calculated.

The study was approved by the Ethics Committee of the National Institute of Nutrition and Food Safety, Chinese Center for Disease Control and Prevention and all the women voluntarily joined the study with informed consent.

\section{Clinical and biomarker measurements}

Several indicators such as haemoglobin, serum iron (SI) and ferritin (FER) have been used as clinical parameters that reflect iron metabolism status. ${ }^{14}$ The ferrozine method was used to measure SI and unsaturated iron binding capacity (UIBC) and immunonephelometry was used to detect FER, transferrin (TF) and C-reactive protein levels. Free erythrocyte protoporphyrin (FEP) was measured by haematofluorometry. Total iron binding capacity (TIBC) and transferrin saturation (TS) were calculated from SI and UIBC (TIBC=SI+UIBC, TS=SI/TIBC).

\section{Statistical analysis}

All data were collected by Epidata 3.02 and data analysis was performed by SAS for Windows V.9.1.3 (SAS Institute, Cary, North Carolina, USA). Descriptive statistics for variables were used with tables, means and SDs. Median (lower quartile, upper quartile) values were used to characterise the diet and non-normal distribution variables. In the data analysis we used the $t$ test for continuous variables with normal distribution while, for nominal (categorical) variables, we used non-parametric tests such as the $\chi^{2}$ test, Fisher exact test or median two-sample test; $p$ values $<0.5$ were considered to be statistically significant. OR and $95 \%$ CIs for anaemia were calculated by univariate regression and multivariate logistic regression after adjustment for possible confounders (age, education level, physical activity time, income, monthly expenditure on food and region).

\section{RESULTS}

The number of women who underwent haemoglobin testing in Huangling, Qidong and Xiuning was 2740, 2088 and 862, respectively and, according to the criteria, 572, 472 and 243 women from the three areas were diagnosed with anaemia. Women with serious diseases and those refused to participate in the project were excluded. The final subjects of cases and controls were 1004 and 1025 respectively with complete questionnaire and blood characters test by consideration of age and living places match.

Table 1 showed the mean age of the control and case groups was comparable (60.8 years vs 61 years). The proportion of people with primary school education and below was $86.4 \%$ in the case group and $86.5 \%$ in the 
Table 1 General information of cases and controls

\begin{tabular}{|c|c|c|c|}
\hline Variables & Cases $(n=1004)$ & Controls $(n=1025)$ & p Value \\
\hline Age (years) & $61.0(7.8)$ & $60.8(7.4)$ & 0.539 \\
\hline Educational level* $(n, \%)$ & 867 (86.4) & $887(86.5)$ & $0.957 \dagger$ \\
\hline Annual income $\neq$ (Yuan, RMB) & $300(0,2000)$ & $500(0,2000)$ & $0.150 \S$ \\
\hline Monthly expenditure on food (Yuan, RMB) & $100(50,150)$ & $100(50,150)$ & $0.797 \S$ \\
\hline Food shortage experience $(n, \%)$ & $452(45.0)$ & $374(36.5)$ & $<0.001 \dagger$ \\
\hline Physical activity time (h/day) & $9.9(2.8)$ & $10.0(2.7)$ & 0.315 \\
\hline
\end{tabular}

${ }^{*}$ Educational level at primary school level and below.

tp Value by Mantel-Haenszel $\chi^{2}$ test.

$\ddagger$ The remaining money except for basic living expenditure, including money from their sons or daughter.

$\S p$ Value by median two-sample test.

ףExposure to the Chinese famine (1959-1961) during childhood.

control group. The annual income in the control group was 500 Yuan (RMB), which was higher than that of cases but the difference was not statistically significant. Monthly expenditure on food was about 100 Yuan (RMB) in both groups. The proportion who experienced food shortage during childhood in the case group was higher than in the control group ( $45.0 \%$ vs $36.5 \%$ ) and the difference was statistically significant $(\mathrm{p}<0.001)$.

The anthropometric measurements were shown in table 2. The average height, weight, BMI and waist circumference of the case group were all significantly lower than those in the control group $(\mathrm{p}<0.001)$. According to the cut-off point of BMI and waist circumference, ${ }^{15}$ $64.2 \%$ of cases and $55.3 \%$ of controls were in the normal range, but $11.1 \%$ of cases a had low BMI, significantly more than in the control group $(\mathrm{p}<0.001)$.

With regard to biomarkers, anaemic women had lower serum total protein, albumin, SI, FER and TS levels $(\mathrm{p}<0.001)$, while FEP and $\mathrm{FEP} / \mathrm{Hb}$ ratio in anaemic women were higher than that in controls $(p<0.001)$. There was no difference for TF and TIBC between cases and controls (table 3 ).

Table 2 Anthropometric assessments of elderly women among cases and controls

\begin{tabular}{lcrr}
\hline Anthropometric measurements & Cases $(\mathbf{n = 1 0 0 4 )}$ & Controls $(\mathbf{n = 1 0 2 5})$ & $\mathbf{p}$ Value \\
\hline Height $(\mathrm{cm})$ & $152.4(6.2)$ & $153.3(5.9)$ & 0.001 \\
Weight $(\mathrm{kg})$ & $51.4(8.7)$ & $54.6(9.5)$ & $23.2(3.5)$ \\
BMI $\left(\mathrm{kg} / \mathrm{m}^{2}\right)$ & $22.1(3.2)$ & $80(7.8)$ & $<0.001$ \\
Low weight $(<18.5)(\mathrm{n}, \%)$ & $111(11.1)$ & $567(55.3)$ \\
Normal $(18.5-23.9)(\mathrm{n}, \%)$ & $644(64.2)$ & $283(27.6)$ \\
Overweight $(24.0-27.9)(\mathrm{n}, \%)$ & $201(19.6)$ & $95(9.3)$ \\
Obesity $(\geq 28.0)(\mathrm{n}, \%)$ & $48(5.1)$ & $78.6(9.2)$ \\
Waist circumference $(\mathrm{cm})$ & $74.4(8.6)$ & $559(54.5)$ \\
Adequate $(<80.0)(\mathrm{n}, \%)$ & $744(74.1)$ & $466(45.5)$ & $<0.001$ \\
Increased $(\geq 80.0)(\mathrm{n}, \%)$ & $260(25.9)$ &
\end{tabular}

Table 3 Blood indices of elderly women among cases and controls

\begin{tabular}{lcrr}
\hline Biochemical indices & Cases $(\mathbf{n}=1004)$ & Controls $(\mathbf{n}=1025)$ & $\mathbf{p}$ Value \\
\hline Haemoglobin $(\mathrm{g} / \mathrm{L})$ & $113.7(6.8)$ & $140.0(8.8)$ & $<1.0(6.3)$ \\
Total protein $(\mathrm{g} / \mathrm{L})$ & $79.3(9.2)$ & $49.4(3.6)$ & $<0.001$ \\
Albumin $(\mathrm{g} / \mathrm{L})$ & $48.1(3.7)$ & $16.4(5.7)$ & $<0.001$ \\
Serum iron $(\mu \mathrm{mol} / \mathrm{L})$ & $13.4(5.4)$ & $131.0(92.0)$ & $<0.001$ \\
Ferritin $(\mu \mathrm{g} / \mathrm{L})$ & $109.6(85.6)$ & $2.6(0.4)$ & $<0.001$ \\
Transferrin $(\mathrm{g} / \mathrm{L})$ & $2.6(0.5)$ & $39.6(17.8)$ & 0.765 \\
Free erythrocyte protoporphyrin $(\mu \mathrm{g} / \mathrm{dL})$ & $42.4(21.2)$ & $62.1(10.1)$ & $26.8(9.6)$ \\
Total iron binding capacity $(\mu \mathrm{mol} / \mathrm{L})$ & $61.2(11.4)$ & $7.9(6.8)$ & 0.001 \\
Transferrin saturation $(\%)$ & $22.5(9.5)$ & $2.8(1.3)$ & $<0.001$ \\
C-reactive protein $(\mathrm{mg} / \mathrm{L})$ & $6.9(8.6)$ & & 0.007 \\
FEP/Hb ratio $(\mu \mathrm{g} / \mathrm{g}, \%)$ & $3.8(2.0)$ & & $<0.001$ \\
\hline FEP, free erythrocyte protoporphyrin. & &
\end{tabular}


Table 4 Food, energy and iron intake in cases and controls (median (lower quartile, upper quartile))

\begin{tabular}{|c|c|c|c|}
\hline Food and nutrient intake & Cases $(n=1004)$ & Controls $(n=1025)$ & p Value* \\
\hline Staple food $†(g)$ & $155.6(114.4,320.8)$ & $155.6(111.1,325.0)$ & 0.875 \\
\hline Animal food $\neq(\mathrm{g})$ & $22.2(0,50.8)$ & $22.2(0,55.6)$ & 0.955 \\
\hline Soy food§ $(g)$ & $0.5(0.3,26.7)$ & $5.6(0.4,27.8)$ & 0.048 \\
\hline Vegetable (g) & $150.0(50.8,283.3)$ & $150.0(44.4,281.7)$ & 0.982 \\
\hline Fruit (g) & $14.8(4.9,41.7)$ & $15.0(5.5,41.7)$ & 0.876 \\
\hline Pure energy food $\emptyset(\mathrm{g})$ & $19.4(13.9,37.2)$ & $18.0(13.9,33.3)$ & 0.163 \\
\hline DBI_LBS & $49(43,53)$ & $49(43,53)$ & 0.490 \\
\hline Total energy intake (MJ) & $7.5(5.8,9.0)$ & $7.5(5.7,9.1)$ & 0.641 \\
\hline Protein intake $(\mathrm{g})$ & $46.1(34.1,60.8)$ & $46.9(34.0,60.7)$ & 0.387 \\
\hline Carbohydrate intake (g) & $273.2(208.6,326.8)$ & $274.8(212.3,333.1)$ & 0.739 \\
\hline Fat intake (g) & $54.0(39.3,68.4)$ & $52.8(38.1,67.9)$ & 0.412 \\
\hline Iron intake (mg) & $17.0(13.7,22.6)$ & $17.0(13.4,21.6)$ & 0.982 \\
\hline
\end{tabular}

${ }^{*}$ p Value by median two-sample test.

†Staple food: containing rice, wheat and other cereals, potatoes.

$\ddagger$ Animal food: containing red meats, poultry, fish, eggs and milk.

$\S$ Soy food: dry beans and bean products (ie, tofu, soymilk), calculated by dry soybean weight.

円Pure energy food: containing sugar, alcohol and edible oil.

DBI_LBS, dietary balance index of lower balance score.

Differences in food intake and main nutrients were shown in table 4. The consumption of soy food in women with anaemia was significantly lower than in the control group $(\mathrm{p}<0.05)$. There was no significant difference in the consumption of staple, animal food, vegetable, fruit and pure energy food between the two groups. Based on the DBI of lower balance score (DBI_LBS), ${ }^{12}$ we made an evaluation of diet quality. The total DBI_LBS score was $0-58$, which was divided into three levels $(<20,20-40,>40)$. The median score was 49 in both the case and control groups.

Three regression models were used to analyse the maximum likelihood ratio (tables 5 and 6). Model 3 was optimal from the statistical and professional point of view.

Table 5 Models for anaemia and influencing factors by logistic regression

\begin{tabular}{|c|c|c|c|c|}
\hline \multirow[b]{2}{*}{ Model } & \multirow[b]{2}{*}{$-2 \log L$} & \multicolumn{3}{|c|}{$\begin{array}{l}\text { Testing global null } \\
\text { hypothesis: } \beta=0\end{array}$} \\
\hline & & $\chi^{2}$ & DF & p Value \\
\hline Model $1^{*}$ & 2329.12 & 483.45 & 29 & $<0.001$ \\
\hline Model $2 \dagger$ & 2347.52 & 465.05 & 12 & $<0.001$ \\
\hline Model 3‡ & 2528.47 & 284.10 & 8 & $<0.001$ \\
\hline Model $4 \S$ & 2534.98 & 277.60 & 6 & $<0.001$ \\
\hline \multicolumn{5}{|c|}{$\begin{array}{l}\text { *Twenty-nine parameters in model } 1 \text { were all variables in tables } \\
1-4 \text {. } \\
\text { †Eight parameters in model } 1 \text { were deleted by } p>0.10 \text { : age, } \\
\text { educational level, annual income, monthly expenditure on food, } \\
\text { physical activity time, vegetable, fruit, animal food, pure energy } \\
\text { food, protein intake, iron intake, DBI_LBS, total energy intake, } \\
\text { carbohydrate intake, transferrin, C-reactive protein. } \\
\text { łParameters in model } 3 \text { were as follows: experience of food } \\
\text { shortage, body mass index, albumin, total protein, ferritin, } \\
\text { transferrin saturation, FEP/Hb ratio and soy food intake. } \\
\text { §Parameters in model } 4 \text { were as follows: experience of food } \\
\text { shortage, body mass index, albumin, total protein, transferrin } \\
\text { saturation, FEP/Hb ratio. } \\
\text { DBI_LBS, dietary balance index of lower balance score; FEP, free } \\
\text { erythrocyte protoporphyrin. }\end{array}$} \\
\hline
\end{tabular}

Table 7 showed the ORs for influencing factors and anaemia by univariate and multivariate logistic regression modelling. After controlling for confounding variables, BMI, experience of food shortage, total protein and albumin were independently related to anaemia.

\section{DISCUSSION}

Anaemia in elderly people has been a public health problem for decades in China but, in comparison with the significant efforts made in pregnant women and children, anaemia in elderly people has received less attention. To our knowledge, this case-control project is the first study to investigate the possible risk of anaemia in rural elderly women. Through the general health survey, diet questionnaire, anthropometric measurements and biochemical analysis, we found that women in the control group had better nutritional status. Although both cases and controls had low food intake as there was no statistical difference in DBI_LBS between the two groups, the average intake of most types of foods in the controls was slightly higher than in the cases. It may be that the long-term small difference in food intake could contribute to the significant difference in biochemical indices and anthropometric measurements.

In China, elderly women play a very important role in family life. They take charge of much of the housework and take care of their grandchildren, but they have a low income. ${ }^{16}$ Elderly women seldom concern themselves with their own health and are more often malnourished. Several reports have shown that the level of education is related to anaemia. Women with a higher level of education pay more attention to their health and are inclined to purchase or select healthy and nutrient-rich foods. ${ }^{17}$ In our study, since the survey sites were located in poor undeveloped areas, no difference 


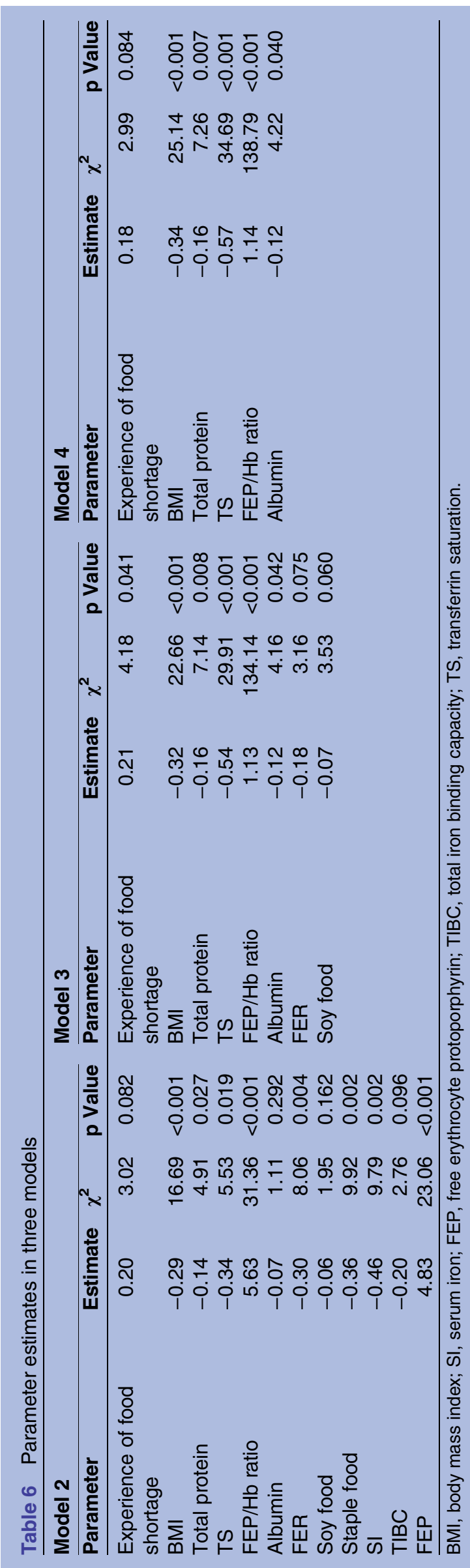

was found in the level of education and annual income between cases and controls. In addition, most elderly women had experienced a poor malnutrition status in the country's economic difficulties during their adolescence and during pregnancy. In our study, by controlling for the main confounding factors, multivariate logistic regression showed that the experience of food shortage was closely related to anaemia, but we could not clarify the direct effect of experiencing food shortage on anaemia. It may be that women who had experienced shortage of food were more likely to remain frugal and to maintain an economic lifestyle. If they maintained this living habit and did not improve their living standard, particularly with regard to the quality of their diet, it would be difficult to improve their poor health. A further retrospective cohort study nested in this study was needed to show the relationship between anaemia and the experience of food shortage.

The fat-free body weight of elderly people will gradually reduce with ageing. BMI, an indicator which reflects fat-free body weight, is a relatively accurate index used by many researchers. Waist circumference is much more valuable for evaluating the fatty body weight component of ageing. ${ }^{18}$ In this study we found that BMI was lower in anaemic women, but most of the women in the case and control groups were in the normal BMI range (18.5-24.0 kg/m ${ }^{2}$ ) according to Chinese criteria. ${ }^{15}$ Our results showed the risk trend of BMI for anaemia. Logistic regression showed that, if BMI values ranged from $<18.5$ to $18.5-23.9 \mathrm{~kg} / \mathrm{m}^{2}$, then the $\mathrm{OR}$ ranged from 1.00 to 0.84 accordingly. The higher the BMI, the lower the OR value. BMI was inversely associated with anaemia. Women with overweight/obesity were less likely to be anaemic than women of normal weight. More work is needed to clarify this issue.

Many studies have shown that diet and nutrition are related to anaemia. Intervention studies to improve anaemia by iron supplementation, ${ }^{19}$ vitamin $\mathrm{B}_{12}{ }^{20}$ or folate fortification have shown them to be efficacious in fighting the problem in this at-risk population and have obtained some encouraging results. However, some studies have suggested that excessive iron stores pose a greater health risk than iron deficiency in the elderly because elevated iron stores have been linked to chronic diseases such as cancer, diabetes and heart disease. ${ }^{21} \mathrm{In}$ anaemia, the main materials for haemoglobin synthesis are iron and protein. The amino acid and polypeptide released from protein could integrate with non-heme iron and form a soluble and absorbable composite. In this study the biochemical indices such as total protein and albumin levels in the case group were much lower than in the controls, which indicates that the protein nutrition status of anaemic women was not as good as in the women in the control group. Both univariate and multivariate regression also showed that blood total protein and albumin were significantly associated with anaemia. However, there was inconsistent information between the protein intake calculated from the three- 
Table 7 Logistic regression model to analyse the influencing factors

\begin{tabular}{|c|c|c|c|c|c|c|}
\hline \multirow[b]{2}{*}{ Variable } & \multicolumn{3}{|c|}{ Univariate regression } & \multicolumn{3}{|c|}{ Multivariate regression* } \\
\hline & $\overline{\text { OR }}$ & $95 \% \mathrm{Cl}$ & p Value & $\overline{\text { OR }}$ & $95 \% \mathrm{Cl}$ & p Value \\
\hline Experience of food shortage & 1.39 & 1.15 to 1.69 & $<0.001$ & 1.66 & 1.26 to 2.19 & $<0.001$ \\
\hline No & 1.00 & & & 1.00 & & \\
\hline Yes & 1.39 & 1.15 to 1.69 & $<0.001$ & 1.66 & 1.26 to 2.19 & $<0.001$ \\
\hline BMI, $\mathrm{kg} / \mathrm{m}^{2}$ & 0.90 & 0.87 to 0.92 & $<0.001$ & 0.89 & 0.87 to 0.92 & $<0.001$ \\
\hline$<18.5$ & 1.00 & & & 1.00 & & \\
\hline $18.5-23.9$ & 0.84 & 0.60 to 1.18 & $<0.001$ & 0.82 & 0.58 to 1.17 & $<0.001$ \\
\hline 23.9-27.9 & 0.46 & 0.31 to 0.67 & 0.006 & 0.44 & 0.30 to 0.65 & 0.005 \\
\hline$>28.0$ & 0.34 & 0.21 to 0.56 & $<0.001$ & 0.33 & 0.20 to 0.55 & $<0.001$ \\
\hline Soy food & 0.94 & 0.78 to 1.15 & 0.528 & 0.91 & 0.74 to 1.11 & 0.349 \\
\hline Q1† (0.5) & 1.00 & & & 1.00 & & \\
\hline Q2† (2.8) & 0.34 & 0.14 to 0.87 & 0.032 & 0.35 & 0.14 to 0.90 & 0.047 \\
\hline Q3† (13.9) & 0.95 & 0.75 to 1.20 & 0.070 & 0.96 & 0.75 to 1.21 & 0.046 \\
\hline Q4† (55.6) & 0.90 & 0.71 to 1.14 & 0.159 & 0.79 & 0.60 to 1.04 & 0.535 \\
\hline Total protein & 0.66 & 0.54 to 0.80 & $<0.001$ & 0.62 & 0.50 to 0.77 & $<0.001$ \\
\hline Q1† (73.3) & 1.00 & & & 1.00 & & \\
\hline $\mathrm{Q} 2 \dagger(78.1)$ & 0.72 & 0.55 to 0.95 & 0.562 & 0.70 & 0.52 to 0.92 & 0.404 \\
\hline Q3† (81.8) & 0.64 & 0.48 to 0.84 & 0.380 & 0.58 & 0.43 to 0.78 & 0.226 \\
\hline Q4† (86.8) & 0.48 & 0.37 to 0.64 & $<0.001$ & 0.43 & 0.32 to 0.59 & $<0.001$ \\
\hline Albumin & 0.72 & 0.59 to 0.87 & $<0.001$ & 0.70 & 0.56 to 0.87 & 0.001 \\
\hline Q1† (44.4) & 1.00 & & & 1.00 & & \\
\hline Q2† (47.6) & 0.74 & 0.57 to 0.98 & 0.686 & 0.72 & 0.54 to 0.96 & 0.516 \\
\hline Q3† (49.9) & 0.62 & 0.47 to 0.81 & 0.077 & 0.58 & 0.43 to 0.78 & 0.054 \\
\hline Q4† (52.8) & 0.58 & 0.44 to 0.76 & 0.012 & 0.52 & 0.37 to 0.72 & 0.004 \\
\hline
\end{tabular}

day food record and blood protein status. As we know, data testing in the laboratory is more accurate than calculation using a food composition table and questionnaire. Because blood total protein and albumin reflect the long-term protein nutrition status, in order to improve protein status an effective strategy to supply sufficient food rich in protein, such as soy food, is needed. Compared with animal foods, soy foods such as tofu, tofu jelly and soy milk are cheap and more accessible, particularly in the poor rural areas of China. However, consumption of only one kind of food does not provide sufficient nutrients and a variety of foods is important for improving one's health. In our study the food intake in both cases and controls was inadequate according to the 'Dietary guideline for Chinese residents', which is probably the reason for the high prevalence of anaemia in the study population. Diet modification is an economic and sustainable measurement for the improvement in anaemia generally, especially in rural areas of China.

In terms of haematological iron status, we selected TS, serum FER concentration and the FEP/haemoglobin ratio to evaluate the stage of IDA. SI represents combined TF iron in the blood circulation and reflects the amount of iron used for haematopoiesis in nucleated red blood cells in the bone marrow. However, SI does not reflect iron storage. SI always falls below $10 \mu \mathrm{mol} / \mathrm{L}^{22}$ in individuals with iron deficiency. Serum FER, TF and TS are indicators of iron stores of the body. ${ }^{23}$ If the TF concentration is normal or depressed while the TS increases, it shows that the body is malnourished or even has chronic disease. ${ }^{24}$ IDA and the anaemia of chronic disease (ACD) are common in elderly people, and the differential diagnosis between the two types of anaemia is challenging because many factors affect iron absorption. Hepcidin ${ }^{25}$ may be a useful indicator of deficient iron stores which regulates iron absorption and recycling by inducing the degradation of ferroportin in the intestine and macrophages. sTfR, ${ }^{26}$ a diagnostic biomarker which distinguishes between IDA and ACD, is always used in the elderly hospitalised population, but the sensitivity and specificity need further testing in elderly persons in the community. The criteria used to classify IDA and ACD differ from one study to another, with one study using a cut-off FER of $22 \mu \mathrm{g} / \mathrm{L}$ to diagnose iron deficiency ${ }^{27}$ while another used a FER level of $30 \mu \mathrm{g} / \mathrm{L}$ as the cut-off limit for exclusion of IDA. ${ }^{28}$ However, IDA and ACD can coexist, so the detection of iron deficiency in the presence of chronic disease can be an important diagnostic challenge. More research is needed to analyse the aetiology of anaemia in the elderly population.

\section{Limitations}

This study has a number of limitations. First, we selected individuals with a haemoglobin level of $90-120 \mathrm{mg} / \mathrm{L}$ as cases and $\geq 130 \mathrm{mg} / \mathrm{L}$ as controls; individuals with 
serious diseases were excluded and the health status of the previous half year was collected by questionnaire, but it did not effectively rule out the possibility of chronic diseases using the questionnaire and the biochemical indices only. Some chronic diseases such as inflammation, infection, tumour and liver diseases could also lead to anaemia, but we could not examine chronic diseases precisely in the study field. We therefore could not differentiate the exact causes of anaemia in these elderly women, particularly in poor rural areas. Second, we measured food intake by consecutive individual three-day food records. Although face-to-face interviews were carried out by experienced investigators, recall bias - particularly in elderly people—was inevitable. Third, the case-control study was designed from effects to causes; women who were anaemic might take measures to improve their anaemia before we conducted the study. However, subjects were questioned about whether haemoglobin tests were conducted previously and the awareness and treatment of anaemia and it was found that the number of women who tested the haemoglobin concentration previously and the awareness of anaemia was very low. The treatment of anaemia was to take drugs but not to improve dietary nutrition and take physical exercise, so we believe that eating habits and physical exercise were stable over time although we did not have sufficient evidence to support our claim. Fourth, when we conducted the logistic regression model, several naturally continuous variables (eg, BMI, income) were categorised for the purpose of analysis, which might have increased the possibility of residual confounding and decreased the precision and power of the study. However, we compensated for this limitation by choosing categories with a number of sufficiently narrow intervals to decrease the residual confounding. Finally, we presented the OR for anaemia by logistic regression in the three rural areas of China, and these findings may not be generalisable to other populations.

\section{CONCLUSION}

Based on the results, the current investigation has two key findings and implications. One is that the overwhelming majority of surveyed elderly women living in poor rural areas were in poor nutritional status because of low food intake. The result of insufficient food and nutrients has implications that increasing whole food quality, such as foods rich in protein, can be defined as an effective strategy. The other key finding is that the blood protein status was associated with anaemia. These findings persisted even after taking account of demographic and socioeconomic indicators. Further research should focus on the aetiology of anaemia in the elderly and also take into account new biomarkers to diagnosis elderly anaemia so that more effective treatments and health education strategies for reduction of anaemia can be robustly conducted.
Acknowledgements We are grateful to all participants in the study. We also thank our colleagues at the laboratory and the staff at the local Centres for Disease Control in Jiangsu, Anhui and Shaanxi Province.

Contributors JZ designed the study. PKS, LPM, QQM, LXL and CRW collected human samples and clinical data. PKS conducted the statistical analysis of the data. PKS and JZ wrote the paper.

Funding This work was supported by research grants from Chinese Nutrition Society Foundation (grant number 05038) and Nestle Foundation for the Study of Problems of Nutrition in the World.(http://www.nestlefoundation.org/ e/docs/AnnualReport2004.pdf)

Competing interests None.

Patient consent Obtained.

Ethics approval Ethics approval was obtained from the Ethics Committee of the Institute of Nutrition and Food Safety, Chinese Center for Disease Control and Prevention.

Provenance and peer review Not commissioned; externally peer reviewed.

Data sharing statement No additional data are available.

Open Access This is an Open Access article distributed in accordance with the Creative Commons Attribution Non Commercial (CC BY-NC 3.0) license, which permits others to distribute, remix, adapt, build upon this work noncommercially, and license their derivative works on different terms, provided the original work is properly cited and the use is non-commercial. See: http:// creativecommons.org/licenses/by-nc/3.0/

\section{REFERENCES}

1. Bruno DB, Erin $\mathrm{M}$, Ines $\mathrm{E}$, et al. Worldwide prevalence of anaemia 1993-2005: WHO global database on anaemia. Geneva: World Health Organization, 2008.

2. Jack MG, Richard SE, Luigi F, et al. Prevalence of anemia in persons 65 years and older in the United States: evidence for a high rate of unexplained anemia. Blood 2004;104:2263-8.

3. Röhrig G, Schulz RJ. Anemia in the elderly. $Z$ Gerontol Geriatr 2013;46:167-76.

4. Ge KY, Chang SY. Studying dietary intake of micronutrients of Chinese inhabitants. Acta Nutrimenta Sinica 1999;21:1-7.

5. Thomson CA, Stanaway JD, Neuhouser ML, et al. Nutrient intake and anemia risk in the Women's Health Initiative observational study. J Am Diet Assoc 2011;111:532-41.

6. Penninx BW, Pahor M, Cesari M, et al. Anemia is associated with disability and decreased physical performance and muscle strength in the elderly. J Am Geriatr Soc 2004;52:719-24.

7. Roy CN. Anemia in frailty. Clin Geriatr Med 2011;27:67-78.

8. Chaves $\mathrm{PH}$, Carlson MC, Ferrucci L, et al. Association between mild anemia and executive function impairment in community-dwelling older women: The Women's Health and Aging Study II. J Am Geriatr Soc 2006;54:1429-35.

9. Denny SD, Kuchibhatla MN, Cohen HJ. Impact of anemia on mortality, cognition, and function in community-dwelling elderly. Am J Med 2006;119:327-34.

10. Mitrache C, Passweg JR, Libura J, et al. Anemia: an indicator for malnutrition in the elderly. Ann Hematol 2001;80:295-8.

11. Yang XG, Kong LZ, Zhai FY, et al. Technical working group of China National Nutrition and Health Survey 2002: general planning of China National Nutrition and Health Survey 2002. Chin J Epidemiol 2005;26:471-4.

12. He YN, Zhai FY, Ge KY. Approaching Chinese diet balance index. $J$ Hygiene Res 2005;34:208-11.

13. Klipstein-Grobusch $\mathrm{K}$, Georg $\mathrm{T}$, Boeing $\mathrm{H}$. Interviewer variability in anthropometric measurements and estimates of body composition. Int J Epidemiol 1997;26:S174-80.

14. WHO. Assessing the iron status of populations including literature reviews: report of a Joint World Health Organization/Centers for Disease Control and prevention technical consultation on the assessment of iron status at the population level. 2nd edn. Geneva: World Health Organization, 2004.

15. Zhou BF. Cooperative Meta-Analysis Group of the Working Group on Obesity in China: predictive values of body mass index and waist circumference to risk factors of related diseases in Chinese adult population. Zhonghua Liu Xing Bing Xue Za Zhi 2002;23:5-10.

16. Ma WJ, Chen MF, Xu YJ, et al. Anemia epidemiological features and determinants in Guangdong province, 2002. South China Prev Med J 2004;30:1-4. 
17. Abdallah TM, Adam I, Abdelhadi MA, et al. Anaemia among adults in Kassala, Eastern Sudan. BMC Res Notes 2012;5:202.

18. Walter W. Nutritional epidemiology. People's Medical Publishing House, 2005:256-7.

19. Chen JS, Zhao XF, Zhang X, et al. Studies on the effectiveness of NaFeEDTA fortified soy sauce in controlling iron deficiency-a population-based intervention trial. J Hygiene Res 2003; 32:S29-38.

20. Alan DD, Elizabeth $\mathrm{A}$, Robert $\mathrm{C}$, et al. A randomised controlled trial investigating the effect of vitamin B12 supplementation on neurological function in healthy older people: the Older People and Enhanced Neurological function (OPEN) study protocol (ISRCTN54195799). Nutr J 2011;10:22.

21. Diana JF, Paul FJ, Katherine LT, et al. Iron status of the free-living, elderly Framingham Heart Study cohort: an iron-replete population with a high prevalence of elevated iron stores. Am J Clin Nutr 2001;73:638-46.
22. Thomas $\mathrm{C}$, Thomas $\mathrm{L}$. Biochemical markers and hematologic indices in the diagnosis of functional iron deficiency. Clin Chem 2002;48:1066-76.

23. Goddard AF, McIntyre AS, Scott BB. Guidelines for the management of iron deficiency anaemia. Gut 2000;46:iv1-5.

24. Weiss G. Pathogenesis and treatment of anaemia of chronic disease. Blood Rev 2002;16:87-96.

25. Sant-Rayn P, Zoe MQ, Mark W, et al. Serum hepcidin as a diagnostic test of iron deficiency in premenopausal female blood donors. Haematology 2011:96:1099-105.

26. Joosten E, Van Loon R, Billen J, et al. Serum transferrin receptor in the evaluation of the iron status in elderly hospitalized patients with anemia. Am J Hematol 2002;69:1-6.

27. Choi CW, Cho WR, Park KH, et al. The cutoff value of serum ferritin for the diagnosis of iron deficiency in community-residing older persons. Ann Hematol 2005;84:358-61.

28. Weiss G, Goodnough LT. Anemia of chronic disease. N Engl J Med 2005;352:1011-23. 